\title{
A realidade cotidiana ficcional. Aproximações do romance latino- americano e a teledramaturgia brasileira
}

Dernival VenÂncio Ramos Júnior

Universidade Federal do Tocantins (Palmas, Brasil)
Plábio Marcos Martins Desidério

Universidade Federal do Tocantins (Palmas, Brasil)

RESUMO: ESTE ARTIGO ANALISA A RELAÇÃO ENTRE A TRADIÇÃO LITERÁRIA LATINO-AMERICANA E A TELENOVELA BRASILEIRA A PARTIR DE PRÁTICAS COMO O MERCHANDISING SOCIAL. ELE OBJETIVA PERCEBER COMO OS ESCRITORES DA FICÇÃO TELEVISIVA, A PARTIR DA RELAÇÃO COM A NARRATIVA LITERÁRIA, COMEÇAM A SE PREOCUPAR EM INSERIR NAS TRAMAS, NAS ÚLTIMAS DÉCADAS, PROBLEMAS COTIDIANOS DA REALIDADE SOCIAL BRASILEIRA.

ABSTRACT: THIS ARTICLE ANALYZES THE RELATIONSHIP BETWEEN THE LITERARY TRADITION OF LATIN AMERICAN AND BRAZILIAN TELENOVELA FROM PRACTICES SUCH AS SOCIAL MERCHANDISING. IT AIMS TO UNDERSTAND, FROM THE RELATIONSHIP WITH THE LITERARY NARRATIVE, HOW THE WRITERS OF TELEVISION DRAMAS BEGIN TO WORRY, IN RECENT DECADES, ABOUT ENTERING IN THE PLOTS PROBLEMS OF EVERYDAY SOCIAL REALITY OF BRAZIL.

PALAVRAS-CHAVE: LITERATURA LATINO-AMERICANA, TELENOVELA, MERCHANDISING SOCIAL.

KEYWORDS: LATIN AMERICAN LITERATURE, TELENOVELA, SOCIAL MERCHANDISING. 
relação entre a literatura e a cultura de massa no Brasil sempre foi complicada. Os poucos que se aventuraram por essa questão preferem marcar as diferenças e distancias. Em geral, os trabalhos se filiam a chamada Escola de Frankfurt. Exemplo disso, o texto "Literatura e Cultura de Massa no Brasil", de Silviano Santiago, desenha a tese de que, nos países periféricos, a literatura teve que constituir sua identidade em oposição à industrial cultural. Essa última, inserida na lógica do mercado, está presa a determinantes dos quais a literatura, historicamente, se afastou.

Este artigo, contudo, tem outro objetivo. Ele trata das relações entre teledramaturgia e literatura. A pesar das diferenças entre a produção literária e a teledramaturgia é possível ver pontos de contato. O que alimenta essa relação é a matriz narrativa latino-americana, que originada no romance, ascendeu à teledramaturgia brasileira a partir de 1960, se consolidando a partir de autores como Dias Gomes.

$\mathrm{Na}$ América Latina, a avanço da Indústria Cultural começou na década de 1960 com a expansão da televisão. Ao mesmo tempo, o romance experimentou um grande salto editorial, com a profissionalização do universo editorial. Para exemplo, Cien años de soledad (1968) de Gabriel García Márquez vendeu, na primeira semana, 8 mil exemplares. Esse sucesso fez de García Márquez um dos primeiros escritores profissionais da região a quem se juntou em seguida Mario Vargas Llosa, Carlos Fuentes, Julio Cortázar, etc.

Esses escritores escreveram para a televisão e para o cinema. García Márquez manteve, durante anos, uma oficina de roteiro para Cinema e Televisão e foi um dos fundadores, em 1986, da Escola Internacional de Cinema e Televisão em Cuba. Várias de seus contos e romances foram adaptados ao cinema, o último deles foi El amor en los tiempos del cólera. No Brasil, o caso Dias Gomes é o mais impactante. Ele foi um dos primeiros, no Brasil, a escrever para a televisão.

A teledramaturgia, em seu início, importou modelos do rádio como o melodrama e o dramalhão. Ela também foi, aos poucos, inserindo a tradição narrativa do romance latino-americano. O trânsito entre territórios ficcionais, do teatro para a televisão, no caso de Dias Gomes, ou do romance para o cinema no caso de García Márquez, enriqueceu a teledramaturgia. Essa é a nossa hipótese.

Segundo Claudia Gilman (2003), é nesse contexto que a narrativa latinoamericana ganhou identidade continental, "cuando esa literatura alcanzó su pico 
máximo de visibilidad y contribuyó a rearmar una nueva tradición literaria" (GILMAN, 2004, p. 19). O engajamento político se afirmou como um dos elementos legitimadores dessa tradição. Como afirma Gilman, "a lo largo de los años de sesenta y setenta la politica constituyó el parámetro de la legitimidad de producción textualy el espacio público fue el escenario privilegiado donde se autorizó la voz del escritor, convertido asi en intelectual' (GILMAN, 2003, p. 29).

Roberto González Echevarría (2001), afirma que o engajamento social é algo recorrente na narrativa latino-americana. Para ele, o romance sempre se utilizou de discursos reconhecidos como produtores da "verdade" social. Nas décadas de 1950 e 1960 surgiram as narrativas-arquivo como Los pañnamanes, de Fanny Buitrago e Libro de Manuel, de Julio Cortázar, que lançam mão de "documentos do real": supostas notícias de jornal, documentos oficiais, cartas, mitos, descrições sociológicas, "relatos orais", que ajudam a criar, para o discurso narrativo, o que Roland Barthes (2004) chamou de "efeito de real." Os "documentos" encontrados pelo leitor dentro de obras ficcionais diluem as fronteiras entre realidade e ficção, pois trazem para dentro da ficção a "realidade".

A narrativa teledramatúrgica, por suas características industriais, potencializa a utilização desses "documentos do real." Em Mulheres apaixonadas, de 2003, alguns personagens foram inseridos numa passeata contra a violência ocorrida na cidade do Rio de Janeiro à época. América, de 2005, inseriu o atentado de 11 de setembro de 2001 através de um personagem-testemunha. Em seguida foram inseridos trechos do Jornal Nacional, que havia noticiando a destruição do World Trade Center, no cotidiano de outros personagens. Os personagens fictícios e os brasileiros participariam da mesma "realidade", experienciariam os mesmos fatos e os veriam representados pelo mesmo noticiário. Aqui se usa as mesmas estratégias da narrativa-arquivo.

As reflexões de Gilman (2003) e González Echeverría (2001) permitem pensar a teledramaturgia brasileira no contexto da matriz narrativa latino-americana, nas estratégias de produção do "efeito de real" e no engajamento social. A ideia de matriz narrativa está em consonância com a ideia de matriz cultural desenvolvida por Jesus Martin-Barbero (2008), que atravessaria a cultura popular, as culturas eruditas e a cultura de massa. A matriz narrativa tem como características o compromisso social e a tentativa de abolir as fronteiras entre realidade e ficção, lançando mão de estratégias como os "documentos do real." 
Renato Ortiz (1991) afirma que no Brasil, a telenovela, nas décadas de 1950 e 1960, foi influenciada, de modo central, pelos folhetins e pela radionovela, narrativas caracterizadas pelo melodrama, com forte presença do "dramalhão". O melodrama, assim, prevalecia nas tramas, pois as radionovelas exacerbavam moralismos e sentimentalismos através de estórias carregadas de lágrimas e "água com açúcar" (OROZ, 1999). Nessa época, a telenovela adaptou romances brasileiros, se assemelhando ao teleteatro, um tipo de teatro adaptado à televisão.

O melodrama surgiu na fase de consolidação da sociedade burguesa, a partir do século XIX (HUPES, 2000). Seus principais elementos, oriundos especialmente do melodrama clássico estão estruturados no maniqueísmo, num amor sempre antirracional e antissocial, na identificação simplificada dos personagens, na caracterização de personagens como o vilão e o cômico e uma moralidade baseada na conduta conservadora e reparadora. Sua moralidade procura conservar a família, a pátria e as virtudes tidas como humanas. Os que negam essa conduta são considerados os vilões (THOMASSEAU, 2005).

O melodrama clássico influenciou as produções dramatúrgicas atuais e se constrói com três atos. O primeiro apresenta os personagens e os elementos da narrativa. O segundo mostra a ação do vilão ou um fato que quebra o equilibrio inicial da história. Por fim, no terceiro ato, a ordem é restabelecida pelo herói e a "donzela" é salva. Esses elementos técnicos, carregados de maniqueísmo entre os personagens, demarcavam nitidamente o papel de cada um, do vilão, do herói e da "donzela". Autores como Louiz Caignierz e René-Charles G. de Pixérécourt trabalharam esses elementos no século XIX, especialmente na França.

Antes da telenovela, a radionovela recebera a influência daqueles elementos do melodrama. Por isso, quando se aponta a relação da radionovela com a telenovela, se reafirma a influência do melodrama sobre a teledramaturgia brasileira. Por outro lado, poucos são os trabalhos que relacionam a telenovela com gêneros narrativos como o romance. Como foi dito, a hipótese é que o engajamento social a que se vinculará a teledramaturgia brasileira advém das discussões relacionadas ao romance latino-americano.

Nessa relação, um elemento central seria o realismo seguido por muitos autores de teledramaturgia como Dias Gomes. Apesar de ser possível identi- 
ficar alguns elementos realistas nas suas produções dramatúrgicas, a hipótese de que é outro o discurso sobre a realidade adotado por ele parece ser mais plausível. Esse discurso estaria ligado ao chamado Realismo Maravilhoso.

Alejo Carpentier, que primeiro teorizou o real maravilhoso na década de 1950, García Márquez, Vargas Llosa, Carlos Fuentes, Júlio Cortázar são alguns dos autores que adotaram e desenvolveram o "real maravilhoso", que seria um discurso sobre a realidade latino-americana: constituída por um padrão cultural diferente, um mundo ainda não desencantado em que o ordinário e o extraordinário são percebidos como constituintes do real (CARPENTIER, 2006).

Dias Gomes, em narrativas dramatúrgicas como em O Bem Amado, fala das contradições da sociedade brasileira, sua complexa relação com o mundo moderno e com as tradições locais a partir de um padrão que se aproxima do Realismo Maravilhoso. Essa preocupação, a partir de 1970, apesar de forte presença de elementos melodramáticos, permeava a teledramaturgia nacional. Assim, a permanência do melodrama não impediu que, a partir da relação com o romance, a telenovela no Brasil procurasse aproximar-se da realidade social, inserindo elementos do cotidiano na narrativa.

Uma telenovela, marco do realismo teledramatúrgico, que se afasta, portanto, da tradição radionovelesca foi Beto Rockefeller (1968/1969), dirigida por Bráulio Pedroso e exibida pela TV Tupi. Nessa novela, o principal personagem, Beto, praticava arrivismo social. O que marcou essa telenovela foi a utilização de expressões linguísticas do cotidiano e a inserção da realidade social de São Paulo. Era proposta uma descrição da classe média ascendente com o milagre econômico brasileiro do período.

A telenovela, portanto, a partir das décadas 1960/70, afastando-se da influência da radionovela, procurou tornar-se cada vez mais "realista". O impacto de discussões sobre a relação narrativa/vida social, iniciada no romance, parece crucial nesse processo. Ela se aproximou da "realidade nacional", incorporando temáticas como o futebol, o sertão, a linguagem cotidiana, etc. Dias Gomes ao inserir a realidade brasileira na teledramaturgia, por exemplo, optou por retratar a difícil relação entre tradição e modernidade. Nesse sentido, eles se aproximam da descrição da realidade social construída pelo Realismo Maravilhoso.

Os autores de telenovelas se aproximam da realidade social de vários modos. A produção Irmãos Coragem (1970) de Janete Clair, produzida pela Rede Globo, imprimiu um ritmo industrial à produção da telenovela. O governo 
militar procurava produzir uma imagem país moderno, de acordo com o "milagre econômico brasileiro.” Nesse período, o Brasil se consagrou tricampeão do mundo de futebol. Nessa telenovela, os autores continuaram a construir uma linguagem mais próxima do cotidiano e das mudanças que o país sofria.

Em Selva de Pedra (1972), exibida pela Rede Globo, Janete Clair, procurou representar esses elementos de modernização no Brasil. Baseada no romance An american tragedy do autor norte-americano Theodore Deiser, a novela tematiza dois extremos familiares. Um irmão bem sucedido, inserido na lógica moderna e capitalista e um irmão que adere a religião tornando-se um fanático. Hambúrguer (2005) aponta que, naquele momento, existia uma preocupação dos escritores em destacar os elementos modernos dos quais a sociedade brasileira estava se apropriando, como bens de consumo industriais.

O universo no qual se move Dias Gomes é próximo ao dessa autora. Um exemplo disso, a novela Roque Santeiro, adaptada de sua peça O Berço do Herói. A primeira versão foi proibida na década de 1970, pois criticava os militares e agredia a moral da época, sendo permitida somente em 1985. Nela, o dramaturgo incorporou elementos comuns no interior do Brasil: clientelismo político, tradição religiosa, etc. No geral, a novela mostra que a modernidade não conseguia substituir a ordem social estabelecida no interior do país. Seguia, assim, o esquema de $O$ Bem Amado, que gira em torno da inauguração do cemitério da cidade. Como não há mortes, o prefeito contrata um pistoleiro para solucionar o problema. Mas quem acaba morrendo é o próprio prefeito Odorico Paraguaçu.

Em Saramandaia (1976), Dias Gomes narrou de modo claro a partir de elementos do Realismo Maravilhoso. O extraordinário e o cotidiano, o moderno e a tradição convivem na cidade de Bole Bole, onde vivia um lobisomem, um homem que solta formigas pelo nariz e uma glutona que explode de tanto comer.

Essas produções se relacionam, assim, com o universo ficcional de autores como García Márquez e Vargas Lhosa, etc., que a partir do Realismo Maravilhoso, se dedicaram a descrever mundos fechados em si, regidos por regras diferentes daquelas da modernidade, como o clientelismo político. Ao discurso de modernização, então em voga, e que era representado pelas obras de infraestrutura do Regime Militar, símbolos da modernização do país, foi confrontado por Dias Gomes ao focar o "outro Brasil," ligado às tradições regionais. 
A discussão sobre a modernidade no Brasil, representada naquele momento pelo crescimento econômico, pela urbanização e pelo consumo de bens como o automóvel, a televisão, etc. estimularam autores de teledramaturgia a analisar as principais transformações da sociedade brasileira. O ponto de referência desses escritores estava centrado no eixo Rio-São Paulo, pois nesses espaços as transformações se tornaram mais evidentes, tornando-se a referência imaginária para a construção de uma cultura nacional. Para alguns, como Janete Clair, o Brasil alcançaria a modernidade ao abrandar a tradição, contudo, para Dias Gomes, a realidade brasileira se apresenta de modo mais complexo.

O mundo da tradição, em choque com a modernidade, é o lugar onde autores do realismo maravilhoso e Dias Gomes ambientaram muitas de suas tramas. Asa Branca, Bole Bole e Sucupira seriam representantes de uma realidade nacional, marcada pela distância do mundo moderno. Neste sentido, Dias Gomes se aproxima de García Marquez em Cien años de soledad, que descreve um povoado distante da capital do país - o centro moderno. Quando foi preciso contactar o governo, enviou um mensageiro "que atravesó la sierra, se extravió en pântanos desmesurados, remonto ríos tormentosos (...) antes de conseguir uma ruta de enlance con las mulas del correo" (GARCÍA MÁRQUEZ, 2003, p. 12). Dentro do contexto modernizante imprimido pelo Regime Militar, a ênfase no Brasil alheio ao moderno, era um modo de questionar o regime e o discurso que o legitimava.

Ao fazer isso, Dias Gomes seguia uma tendência já comum em suas peças de teatro como é o caso de O Pagador de Promessas, onde os mundos do interior e o mundo urbano se encontram. Zé-do-Burro faz uma espécie de viagem simbólica do tradicional, da cidade do interior, à Salvador, uma cidade em pleno processo de modernização. Sua jornada pode representar a tentativa do país de ir do tradicional ao moderno. Mas Zé-do-Burro, mesmo no contexto urbano, ainda se move a partir de valores ligados à tradição e sofre com o arrivismo e outros problemas ligados ao "novo" país.

Ao escrever para a televisão, Dias Gomes adaptou algumas de suas peças para a teledramaturgia, e continuou, como antes, a problematizar e criticar questões da realidade brasileira como é possível ver em Roque Santeiro, O Bem amado, Saramandaia. A última produção de Dias Gomes foi a minissérie Decadência (1995), em que abordou fanatismo religioso e enriquecimento através da religião, eleição e impeachment presidencial, bem como uma rápida tematização ideológica entre uma militante de um partido de esquerda e um líder religioso. 
Essas obras são exemplos de como Dias Gomes estava atento aos problemas e questões colocadas pela realidade social que o cercava. Ele realizou uma crítica social incorporando elementos da realidade brasileira, problematizando a inserção do país na modernidade, ao tematizar o mundo do interior do país, onde a modernidade acabou por não chegar (RIDENTI, 2000). Ele e Janete Clair dão início a um padrão que hoje é seguido por autores como Gloria Perez, Benedito Rui Barbosa e Manoel Carlos.

\section{III}

Escritores de telenovelas como Gloria Perez, Benedito Rui Barbosa e Manoel Carlos, etc., incluíram em suas narrativas, nas últimas décadas, temas da realidade nacional - mesmo tendo influência do melodrama -, inserindo na ficção, questões não ficcionais, através de "documentos do real." Benedito Rui Barbosa nas novelas, O Rei do Gado, procurou explorar duas temáticas: a honestidade e o ativismo político por parte de um senador da República e a questão do movimento social MST (Movimento dos Sem Terra).

A história narra a luta entre duas famílias rivais: Mezenga e Berdinazi, retratando inicialmente a primeira geração dessas famílias italianas no Brasil. No momento posterior, é narrada a "saga" de Bruno Mezenga (Antonio Fagundes), que se estabelece como o "rei do gado". Essa é a trama central e junto a elas, outras tramas se desenvolvem como ação política do senador Caxias e do movimento Sem-Terra. O destaque dado ao senador Caxias objetivava retratar um político honesto dentro das relações políticas do Congresso $\mathrm{Na}$ cional. Também se retratou os problemas sociais no campo, que acabam por vitimar o senador Caxias, numa emboscada preparada para alvejar os "semterra" que este apoiava.

Outros escritores seguiram essa tendência. Escritores como Glória Perez e Manoel Carlos são exemplos de como essa preocupação tornou-se constante a partir da década de 1990. Esses escritores procuravam discutir temas da realidade cotidiana acentuando o caráter didático dessas inserções: a necessidade de educar e conscientizar o público.

Nesse sentido, as tramas estão recheadas de questões do cotidiano: violência urbana e doméstica, dependência química, transplantes, portadores de 
necessidades especiais (físico e mental) foram inseridos na ficção por Manoel e Glória Perez. Essa maior aproximação com a realidade, realizando essas inserções de ações pedagógicas na ficção televisiva tornou-se uma das características marcantes da telenovela contemporânea.

Usando como referência uma de suas novelas Laços de Família (2000/2001), Manoel Carlos promoveu campanhas sociais de doação de órgãos. Outras procuraram promover campanhas, como o respeito aos idosos e o debate sobre a violência contra as mulheres, em Mulheres apaixonadas (2003). A relação da sociedade e os portadores de necessidades especiais estavam presentes em Páginas da Vida (2006/2007), (ALENCAR, 2004).

Glória Perez em sua primeira telenovela Barriga de Aluguel (1990/1991), procurou tematizar um problema bioético sobre inseminação artificial em um útero alugado. Nas suas telenovelas seguintes, esteve presente a inserção de temáticas que procuraram servir como espaço de utilidade pública. Pode-se identificar em suas novelas, como De Corpo e Alma (1992/1993), discussões sobre o transplante de órgãos. Em outra novela, Explode Coração (1995/1996), a escritora tematizou o desaparecimento de crianças. Em seu maior sucesso, O Clone (2001/2002), discutiu o problema das drogas.

Em outra novela, América (2005), Glória Perez apresentou como os portadores de necessidades especiais, nesse caso, pessoas com deficiência visual se inserem na sociedade. Em sua última novela, Caminho das Índias (2009) discutiu a questão da esquizofrenia como uma psicopatia. Essas ações foram destacas por serem as mais relevantes no interior na trama, porém várias outras ocorreram no desenrolar da ficção.

Manoel Carlos e Glória Perez, para exemplos, inserem campanhas sociais nas novelas. Essa prática também é conhecida como merchandising social. Ele se tornou uma presença constante em quase todas as suas novelas nas últimas décadas. Assim, a partir da década de 1990, podem ser caracterizadas como novelas de intervenção, por se preocupar em retratar o cotidiano e se portar como canal de utilidade pública, discutindo diversos temas da vida diária dos seus telespectadores (OBITEL, 2009). Essas questões sociais funcionam como "documentos do real", ajudando a diluir as fronteiras entre o real e o ficcional.

A preocupação entre aqueles escritores da Rede Globo está presente nas novelas de Benedito Ruy Barbosa. Esse movimento, de variada motivação, algumas oriundas da televisão, foi impulsionado por formatos jornalísticos 
como Aqui Agora, que procurava fornecer serviços à população e ser mais efetivo junto aos telespectadores, tentando se aproximar do público (HAMBURGER, 2005).

A inserção do chamado merchandising social nas telenovelas mostra que essas lançam mão de estratégias retóricas e estilísticas semelhantes às dos romancistas latino-americanos, "documentos" que ajudam a produzir um "efeito de real” (BARTHES, 2004) para as tramas. Glória Perez, por exemplo, em O Clone, utilizou testemunhos de pessoas reais, o que acabava por reforçar a relação entre a trama e o mundo real.

\section{IV}

As várias características da telenovela contemporânea, na virada do século XXI, são o resultado de diversas variáveis. A herança do melodrama e do folhetim é algo que permanece, mas essa adequação à realidade imediata, a perseguição constante do cotidiano torna-se uma constante na sua produção. A TV por assinatura e os reality shows são elementos que motivaram a adequação da telenovela a essa nova "pressão" por adequação à realidade (HAMBURGER, 2005).

A Rede Globo se mantém, nesse final da primeira década do século XXI, como a maior produtora de telenovelas do país e procura preservar seu casting (autores/atores consagrados) do gênero, pelo menos para a teledramaturgia. Porém, outras emissoras procuram investir na produção dramatúrgica, principalmente de novelas. Segundo estudos como o OBITEL, a ficção televisiva no Brasil aumentou expressivamente, na quantidade de horas veiculadas na grade de programação das principais emissoras de TV aberta no país (OBITEL, 2009).

A telenovela, o principal formato da ficção televisiva brasileira, continua sendo um produto estratégico, adaptando-se e modificando suas características. O merchandising social tornou-se uma estratégia central e contribui para ela se renovar e continuar nesse posto. Outros elementos, com a interação por meio da internet, propiciaram novas formas de relacionamento de público/telenovela.

Seria anacronismo considerar Dias Gomes aquele que inaugurou o uso do merchandising social, pois o dramaturgo tinha preocupações diferentes dos tele- 
dramaturgos da atualidade. No entanto, como mostramos acima, o dramaturgo procurou a todo instante aproximar sua ficção da realidade brasileira, e por isso criticar várias situações da sociedade brasileira. A sua militância intelectual, derivada do contexto literário e político latino-americano que o cercava, levou-o a inserir a realidade social como elemento central de suas telenovelas.

Nesse sentido, seu impacto na estruturação de um padrão de narrativa para a telenovela deve ser lembrado. Ele afastou a telenovela brasileira dos dramalhões tão comuns no momento anterior e levou-a a se tornar um tipo de produção cultural que se define, hoje, pela tentativa de discutir problemas do real e pela inserção de "documentos do real". O merchandising social tornou-se uma estratégia de diluição das fronteiras entre real e ficcional, bem como uma tentativa de tematizar problemas do cotidiano nacional.

\section{Referências bibliográficas}

ALENCAR, Mauro. A Hollywood brasileira. São Paulo: Senac Editora, 2004.

BARTHES, R. O rumor da língua. São Paulo: Martins Fontes, 2004.

CARPENTIER, Alejo. El reino de este mundo. Madrid: Alianza, 2006.

ECHEVARRÍA, Roberto González. Mito e archivo. México: FCE, 2001.

FILHO, João Freire. A TV, os intelectuais e a massa no Brasil (1950-1980). Ciberlegenda. Numero 11. 2003. http://www.uff.br/mestcii/joao1.htm, visitado em 25/06/2010.

GARCÍA MÁRQUEZ, Gabriel. Cien años de soledad. Bogotá: Norma, 2003.

GILMAN, Claúdia. Entre la pluma y el fuzil. Debates e dilemas del escritor revolucionário em América Latina. Buenos Aires: Siglo Veinte Editores, 2003.

HAMBURGER, Esther. O Brasil antenado: a sociedade da novela. Rio de Janeiro: Jorge Zahar, 2005.

HUPPES, Ivete. O melodrama. São Paulo: Ateliê Editorial, 2000.

MARTIN-BARBEIRO, Jesus. Meios e mediações. Rio de Janeiro: Editora UFRJ, 2008.

MARTIN, Gerald. Gabriel García Márquez. Una vida. Barcelona: Debate, 2009.

ORTIZ, Renato et al. Telenovela: história e produção. São Paulo: Brasiliense, 1991.

OBITEL. Observatório Ibero-americano de ficção televisiva. Coordenadores: Maria Immacolata Vassallo de Lopes e Guilherme Orozco Gómez. Rio de Janeiro: Editora Globo, 2009.

OROZ, Silvia. O cinema de lágrimas da América Latina. 2a . ed. Rio de Janeiro: Funarte, 1999. 
RIDENTI, Marcelo. Em busca do povo brasileiro: artistas da revolução, do CPC à era da TV. Rio de Janeiro: Record, 2000.

SANTIAGO, Silviano. Literatura e Cultura de Massa no Brasil. In O cosmopolitismo pobre. Belo Horizonte: UFMG, 2004, p.106-124.

THOMASSEAU, Jean Marie. O melodrama. São Paulo: Perspectiva, 2005.

Recebido em 03 de maio e aprovado em 15 de junho de 2011. 